\title{
Política de FinANCIAMENTO DA EDUCAÇÃO SUPERIOR BRASILEIRA: UM BALANÇO CRÍTICO DA PRODUÇÃO ESCRITA NO PERÍODO DE 1996 A 2009*
}

\author{
Vera lúcia Jacob Chaves, \\ da Universidade Federal do Pará \\ André Rodrigues GuIMARÃES, \\ da Universidade Federal do Pará \\ Nabiha Haddad SimÕes Machado, \\ da Universidade de Brasilía
}

\begin{abstract}
Resumo: o artigo expõe resultados da primeira etapa da pesquisa "Política de financiamento na expansão da Educação Superior no Brasil pós-LDB" e se propõe a apresentar uma análise crítica sobre a produção escrita acerca da temática política de financiamento da educação superior, no período de 1996 a 2009. Para o desenvolvimento do trabalho foram selecionados textos publicados em cinco periódicos nacionais. Os resultados apontam que as pesquisas sobre a temática têm sido escassas, evidenciando a necessidade de ampliação dos estudos sobre financiamento da Educação Superior devido à relevância desse assunto para a compreensão das políticas educacionais.

Palavras-chave: Política de financiamento. Recursos públicos. Fundos públicos. Vinculação de recursos.
\end{abstract}

INTRODUZINDO A TEMÁTICA

Este estudo teve como objetivo central analisar a temática política de financiamento da educação superior a partir de um balanço crítico da produção escrita no período de 1996 a 2009.

\footnotetext{
* Artigo recebido em 18/08/2011 e aprovado em 15/09/2011.

O artigo é resultado de pesquisa financiada pelo CNPq e faz parte do Projeto Integrado de Pesquisa da Rede Universitas/Br "Políticas de Expansão da Educação Superior no Brasil pós LDB".
} 
Adotamos como recurso metodológico a bibliografia anotada da produção escrita, tendo como critérios para a definição das fontes publicações de periódicos nacionais, com indexação internacional e nacional na área da educação, conforme a qualificação ${ }^{1}$ da Coordenação de Aperfeiçoamento de Pessoal de Nível Superior (Capes). Foi definido, ainda, que o período das publicações seria o compreendido entre 1996 e 2009. A busca das publicações foi realizada em sítios da internet e em bibliotecas institucionais, como a Biblioteca Central da UnB e da UFPA.

Os periódicos selecionados foram: Revista Brasileira de Educação² (RBE), Qualis A1, Educação \& Sociedade ${ }^{3}$, Qualis A1, Revista de Avaliação da Educação Superior ${ }^{4}$, Qualis A2, Revista Brasileira de Estudos Pedagógicos (RBPE) $)^{5}$, Qualis B1, Universidade e Sociedade ${ }^{6}$, Qualis B4. Para a triagem inicial das publicações foram utilizadas as seguintes palavras-chave: financiamento, expansão e Educação Superior. Posteriormente, foram considerados os nomes dos autores das publicações preliminarmente localizadas, para uma revisão do rastreamento, inclusive com verificação das produções registradas nos currículos hospedados na Plataforma Lattes.

Seguindo essas diretrizes teórico-metodológicas, trabalhamos com um rol de quarenta textos que tratam do financiamento da Educação Superior como temática central ou que a abordam relacionada a outras questões, como Reforma do Estado, organismos internacionais e expansão da Educação Superior.

Organizamos o artigo em dois tópicos. No primeiro momento, buscamos mapear a temática na produção escrita selecionada para o estudo, apontando a frequência ao longo do período, por fonte, e as questões centrais que têm preocupado os autores de modo geral. No segundo momento, detivemo-nos no conteúdo sobre o qual se efetua a discussão acerca da política de financiamento em cada produção, buscando capturar os eixos de preocupação e os sentidos estabelecidos pelas vozes situadas em diferentes lugares sociais e políticos do dizer, sinalizadores da política de financiamento da Educação Superior adotada no Brasil no período em análise.

\section{TRAJETÓRIA DA TEMÁTICA FINANCIAMENTO DA EDUCAÇÃo SUPERIOR}

No exame da produção escrita sobre financiamento da Educação Superior publicada nos cinco periódicos escolhidos, identificamos um conjunto de quarenta artigos que tratam da temática (como foco central ou secundário), no período de 1996 a 2009.

O periódico Universidade e Sociedade apresenta a maior densidade textual sobre a temática, com dezenove artigos publicados no período, segui- 
do da revista Educação e Sociedade, com sete artigos. Já a Revista Avaliação publicou apenas quatro artigos de um mesmo autor, evidenciando a pouca importância que vem sendo dada a estudos dessa natureza. Isso é reforçado em duas outras revistas de referência na área da educação (RBE e RBEP), onde identificamos a ausência de textos que tenham como foco central o estudo sobre a política de financiamento da Educação Superior. Nos nove artigos analisados na RBEP, os autores manifestam a preocupação com a questão do financiamento da educação de modo amplo, relacionada à discussão sobre fundos, gastos, custos, fiscalização e vinculação de recursos, dentre outros aspectos. Os dois artigos publicados na RBE tratam da questão do financiamento como parte de uma política global relacionando-a com a reforma universitária e como parte das diretrizes dos organismos internacionais para a Educação Superior brasileira.

Observando a distribuição dos artigos publicados no período analisado (Tabela 1), destacam-se os anos de 2004 e 2008, nos quais a produção sobre a temática atinge o maior volume, com a publicação de cinco e seis artigos respectivamente em cada ano.

Tabela 1 - Produção escrita sobre financiamento da educação superior - 1996 a 2009.

\begin{tabular}{|c|c|c|c|c|c|c|}
\hline ANO & $\begin{array}{c}\text { Universidade } \\
\text { e Sociedade }\end{array}$ & $\begin{array}{c}\text { Educação e } \\
\text { Sociedade }\end{array}$ & Avaliação & RBE & RBEP & TOTAL \\
\hline 1996 & - & - & - & - & - & - \\
\hline 1997 & 1 & - & 1 & - & - & 2 \\
\hline 1998 & 1 & - & 1 & - & - & 2 \\
\hline 1999 & - & - & - & - & 2 & 2 \\
\hline 2000 & - & - & - & - & - & - \\
\hline 2001 & 1 & - & - & - & 2 & 3 \\
\hline 2002 & 2 & - & - & - & 1 & 3 \\
\hline 2003 & 3 & - & - & - & - & 3 \\
\hline 2004 & 1 & 3 & 1 & - & - & 5 \\
\hline 2005 & 1 & 2 & - & 1 & - & 4 \\
\hline 2006 & 1 & 1 & - & - & 1 & 3 \\
\hline 2007 & 1 & - & - & - & 2 & 3 \\
\hline 2008 & 4 & - & 1 & 1 & - & 6 \\
\hline 2009 & 2 & 1 & - & - & 1 & 4 \\
\hline Total & 18 & 7 & 4 & 2 & 9 & 40 \\
\hline
\end{tabular}

A Tabela 1 evidencia, ainda, a ausência da produção escrita nos anos de 1996 e 2000. Essa baixa densidade discursiva sobre um assunto de extrema relevância para a compreensão das políticas educacionais, em especial 
da situação de crise vivenciada na Educação Superior, indica a dificuldade na realização de estudos dessa natureza e a necessidade de formação de pesquisadores que detenham esse tipo de conhecimento específico.

É importante assinalar que o período definido para o estudo foi marcado pela adoção de uma série de ações governamentais que, no seu conjunto, indicam a opção pela implementação da política neoliberal, materializada pela redução de recursos, pela utilização de mecanismos de controle e pela avaliação com ênfase na busca da eficiência e eficácia. Nesse contexto, os artigos publicados apresentam conteúdo de caráter denunciativo, com críticas às políticas de financiamento implementadas pelos governos brasileiros, relacionando-as ao modelo de Estado gerencialista e às interferências dos organismos internacionais.

De modo geral, o conteúdo dos textos expõe a organização da estrutura de financiamento da educação brasileira; a forma de gestão dos recursos pelos agentes educativos; a relação dos entes federados evidenciando a difícil articulação financeira entre as esferas estaduais, municipais e federal; as formas de financiamento existentes no sistema de ensino; os custos de uma educação de qualidade na esfera pública e privada; os gastos com educação, em especial a relação dos gastos com o Produto Interno Bruto (PIB) e o custoaluno; a fiscalização na aplicação das verbas públicas destinadas à educação e o papel dos Tribunais de Contas dos estados; a vinculação de recursos para a educação; a criação de fundos públicos de financiamento; dentre outros aspectos, como será detalhado a seguir.

A POLÍTICA DE FINANCIAMENTO DA EDUCAÇÃO SUPERIOR NA PRODUÇÃO ESCRITA DE 1996 A 2009.

\section{Revista Universidade e Sociedade}

A Revista Universidade e Sociedade é um periódico semestral ${ }^{7}$ do Sindicato Nacional dos Docentes das Instituições de Ensino Superior (ANDES-SN) e foi a que apresentou o maior volume de artigos publicados no período de investigação, sendo encontrados dezoito trabalhos que tratam do financiamento da Educação Superior. Em dois terços dessa publicação, doze textos, a temática é analisada como categoria central de estudo e os demais a utilizaram de forma secundária. No primeiro grupo, é possível identificar como subcategorias analíticas: financiamento da política de Ciência \& Tecnologia (C\&T); aspectos legais do financiamento educacional; recursos orçamentários da educação; transferências de recursos públicos para Instituições de Ensino Superior (IES) privadas e discussões ou estudos gerais sobre o financiamento 
da educação no Brasil. Já os artigos que tratam a temática de forma secundária, articulam-na com a política econômica brasileira ou a discutem a partir da expansão das vagas na graduação das IES federais, com ênfase na instituição do Programa de Reestruturação e Expansão das Universidades Públicas Federais (Reuni).

O texto de Chaves (2008) analisa a política de financiamento da pesquisa adotada no país a partir dos fundos setoriais. Considerando os dados orçamentários da C\&T do período 2000-2006 em comparação ao orçamento geral da União e ao PIB, evidencia que, mesmo diante da elevação do orçamento na área no primeiro mandato do governo Lula, os valores aplicados ainda são incipientes diante do PIB. A autora relaciona o financiamento da pesquisa com a política de C\&T implementada no país, que se fundamenta na parceria público-privada e na centralidade do mercado.

Quatro artigos abordam o financiamento da educação a partir da legislação brasileira. Amaral (2003) analisa o processo histórico de financiamento da Educação Superior pública no Brasil, com destaque para o estabelecido em nossas constituições. Davies (1997; 2001) considera a temática, em textos distintos, em estudos sobre a Lei de Diretrizes e Bases da Educação Nacional (LDB) - Lei 9.394/1996 - e o Plano Nacional de Educação (PNE) - Lei $10.172 / 2001$. Quanto à LDB, analisa os aspectos positivos e negativos no tocante aos recursos da educação. Com relação ao PNE, evidencia a manutenção da política neoliberal, que negligencia o orçamento educacional. Bosi \& Reis (2003) discutem, considerando os artigos 207 e 212 da Constituição Federal de 1988, a autonomia e manutenção financeira das universidades públicas. Defendem a responsabilidade estatal na manutenção integral dessas universidades, sem necessidade de qualquer outra regulamentação, e se posicionam contrários à fixação de repasses mínimos, vinculados a certos impostos. Os quatro textos consideram a política de ajuste fiscal desenvolvida a partir da década de 1990, que, com medidas legais, leva à redução dos recursos destinados à educação.

Três artigos publicados em anos distintos estudam os recursos financeiros expressos no orçamento federal. Os autores, unanimemente, evidenciam a redução no orçamento das instituições federais de ensino superior (IFES). Sevilha (1998), considerando os anos 1994 e 1998, evidencia que há uma queda no orçamento das universidades federais em relação ao percentual do PIB: 0,53\% e 0,32\%, respectivamente. Miraglia \& Smaili (2002), tendo como referência o ano 2000 em comparação a 1995, afirmam que há uma queda de $19 \%$ nos recursos aplicados no financiamento da Educação Superior pública (considerando valores corrigidos pelo menor índice inflacio- 
nário do período) e, no mesmo período, verificou-se uma expansão de $30 \%$ das vagas na graduação presencial. Já Tonegutti (2007) apresenta um estudo comparativo entre os anos 2002 e 2005 , em que observa um aumento nas despesas líquidas corrigidas, de $\mathrm{R} \$ 3,1$ bilhões, no orçamento educacional (na esfera federal, o aumento é de $\mathrm{R} \$ 0,1$ bilhão), mas uma redução em relação ao PIB, na ordem de $0,5 \%$ (na esfera federal, a queda é de $0,2 \%$ ).

O artigo de Davies (2002) objetivou realizar um exame dos mecanismos de financiamento das instituições privadas, com ênfase na utilização (direta e indireta) de recursos públicos. Para tanto, explora os fundamentos legais e algumas informações oficiais e jornalísticas para demonstrar o que são os recursos públicos recebidos de forma direta - bolsas, crédito educativo ou Programa de Financiamento Estudantil (FIES), empréstimos, subvenções e subsídios diretos - ou indireta - isenções tributárias, previdenciárias e salário educação - que mantêm as IES privadas. Conclui que essa forma de transferência de recursos públicos ao setor privado se trata de uma política governamental deliberadamente privatista.

Três textos analisam o financiamento da Educação Superior de modo geral. Chaves e Vasconcelos (2003) analisam, na revista Universidade e Sociedade, a produção sobre financiamento da educação no período de 1991-2002. Identificam criticamente o conteúdo e a forma dos textos, bem como os agrupamentos específicos e emergentes. Já em 2004, Helene (2004), analisa equívocos comuns na análise do financiamento da Educação Superior no Brasil: o custo aluno em IES públicas e privadas, a renda dos alunos e a natureza da instituição (pública privada), a existência de vagas e a qualidade do ensino superior privado. Davies (2005) analisa detalhadamente as ações do governo Lula da Silva, a maioria indicadas pelo Grupo de Trabalho Interministerial (GTI), que aprofundaram o sucateamento da universidade pública, como a manutenção da Desvinculação das Receitas da União (DRU) e a redução orçamentária, e o incentivo à privatização do ensino superior.

Seis artigos discutem o financiamento da Educação Superior como categoria secundária. Três textos fazem considerações sobre o financiamento da Educação Superior federal, a partir da análise da política econômica brasileira. Dois textos (LIMA, LIMA, 2006; CARNEIRO, 2008) destacam a política de submissão nacional reafirmada por Lula da Silva e expressa na manutenção dos cortes no orçamento social para pagamento das dívidas externas e internas. Concluem que isso tem agravado o quadro caótico e a privatização da universidade pública. Na mesma perspectiva, Pinto, Lima e Cislaghi (2009) indicam que, diante da crise financeira do capital, a tendência de corte nos gastos sociais afeta negativamente as universidades públicas. Essas autoras 
corroboram Carneiro (2008) ao enfatizar, por meio de dados orçamentários, que, com o Reuni, não ocorreu aumento real dos recursos das universidades federais.

Outros três artigos (Tonegutti, MartineZ, 2008; Lima, 2008; Siqueira, 2009) abordam alguns dados orçamentários da educação a partir da análise da expansão do acesso ao ensino superior federal, com ênfase na instituição do Reuni. Em linhas gerais, os autores evidenciam a articulação do Reuni ao processo geral de adequação da universidade aos interesses do capital, expressos no governo Lula da Silva. Destacam que a expansão das vagas via Reuni não terá proporcional aumento de recursos.

Considerando a produção sobre financiamento da Educação Superior na revista Universidade e Sociedade, identificamos a presença constante da temática - dos quatorze anos analisados, o debate se fez presente em onze. Entretanto, percebemos algumas lacunas que precisam ser exploradas em estudos posteriores: há a necessidade de os estudos aprofundarem o debate sobre a questão orçamentária e sua análise articulados com a expansão das vagas. Também é preciso considerar que apenas um estudo se deteve na análise sobre a transferência de recursos públicos para as IES privadas; diante da política deliberada de privatização da universidade, essa análise deve ser elucidada com outras pesquisas.

\section{Revista Educação \& Sociedade}

A revista Educação \& Sociedade, periódico quadrimestral ${ }^{8}$ do Centro de Estudos Educação e Sociedade (CEDES/Unicamp), publicou, no período investigado, sete artigos sobre o financiamento da Educação Superior (em seis números dos sessenta publicados). Dos textos selecionados, quatro abordam o financiamento como temática central e três, de forma secundária. No primeiro grupo, a temática foi abordada por meio da política de Educação Superior implantada no Brasil, dos recursos financeiros (receitas próprias) das IFES e do incentivo fiscal às IES privadas. No segundo grupo, discutiu-se a temática a partir da expansão do ensino superior brasileiro, da privatização do conhecimento e da universidade, bem como do processo de mercantilização e financeirização da Educação Superior.

Dois textos discutem o financiamento da Educação Superior no Brasil a partir da política de Educação Superior brasileira. Davies (2004) faz uma análise de como o governo Lula conduz o financiamento da educação, ressaltando a manutenção do ideário neoliberal. Corbucci (2004) faz uma discussão genérica sobre a temática, considerando a década de 1990. Para o autor, destacando dados da UnB, ainda que seja imprescindível a manuten- 
ção pública das IFES, é preciso que as instituições busquem outras formas de manutenção (públicas ou privadas).

Também utilizando dados do orçamento da UnB, mas com análise sobre os recursos financeiros, principalmente os provenientes de receitas próprias, Velloso e Marques (2005) analisam a evolução dos recursos dessa universidade, de 1989 a 2003, no contexto macro de financiamento das IFES. Defendem, explicitamente, a responsabilidade da União na manutenção das universidades federais e enfatizam a liberdade das IFES para a captação externa de recursos.

Carvalho (2006) discute o financiamento da Educação Superior com foco no incentivo fiscal do Estado às instituições privadas. Analisa o Programa Universidade para Todos (ProUni) como parte da política de ajuste fiscal do Estado brasileiro, que, ao mesmo tempo em que congela os recursos das IFES, cria mecanismos para expansão do mercado da Educação Superior. Destaca que o jogo político na elaboração do Programa e sua implantação evidenciam sua função privatista, questionando o discurso de democratização do acesso ao ensino superior.

Três artigos abordam a questão do financiamento como categoria secundária. Pinto (2004) discute o financiamento a partir da expansão do ensino superior no Brasil, da década 1970 a 2002. Expõe que a expansão nas IFES ocorre em taxas elevadas, na casa de $82 \%$, no período de $1990-2002$, mas com contenção de gastos e de contratação de docentes. Faz críticas ao ProUni e à perspectiva do governo federal de dobrar o número de vagas nas IFES sem considerar a necessidade de elevação orçamentária.

Sguissardi (2005) analisa a mudança na concepção de conhecimento produzido pela universidade pública. Evidencia o abandono da concepção de conhecimento público com uma adesão à perspectiva privado-mercantil. Para as IFES, isso se manifesta por meio de um crescente contingenciamento do seu orçamento federal e na busca de fontes alternativas de recursos (via fundações de apoio). Para subsidiar sua tese, apresenta dados financeiros das IFES com base na comparação com o percentual do PIB de 1989 a 2002.

Oliveira (2009) analisa o processo de mercantilização da Educação Superior no Brasil a partir da introdução dos fundos financeiros nas IES privadas. Aborda, de forma secundária, a questão do financiamento, ao destacar os valores envolvidos em transações financeiras na compra de IES e a estimativa de recursos que essas instituições movimentam anualmente ( $\mathrm{R} \$ 90$ bilhões, cerca de $3 \%$ do PIB).

De modo geral, ainda que todos os textos selecionados considerem a política federal de contingenciamento dos recursos das IFES e a privati- 
zação da Educação Superior, as discussões são distintas e as posições, por vezes, antagônicas. A maioria dos autores (DAVIES, 2004; PINTO, 2004; SGUISSARDI, 2005; Carvalho, 2006; Oliveira, 2009) denunciam o processo de privatização da Educação Superior brasileira e indicam a responsabilidade estatal com a manutenção integral das IFES. Por outro lado, dois artigos (CORBUCCI, 2004; VelLoso, MARQUES, 2005) ainda que reafirmem ser fundamental o financiamento público das IFES, apontam a necessidade de captação de recursos próprios.

\section{Avaliação: Revista da Avaliação da Educação Superior}

Na perspectiva de realizar um levantamento sistemático das publicações científicas do periódico Avaliação: Revista da Avaliação da Educação Superior que abordam o financiamento da Educação Superior como temática central de sua discussão, encontramos quatro artigos, todos de autoria de Amaral (1997, 1998, 2004, 2008).

No trabalho publicado em 1997, Amaral detalha a composição do Sistema Federal de Ensino Superior e a forma de organização e financiamento da educação no Brasil, por esfera do poder público. Conclui que os recursos financeiros para a educação deveriam originar-se da arrecadação de impostos, sem que houvesse cobrança de mensalidades; que o país tem condições de dobrar os recursos públicos para a educação; que há pontos de estrangulamento a serem resolvidos (como aumento de vagas na Educação Superior, defasagens salariais, falta de equipamentos, critérios para a divisão do orçamento, etc.).

Em outra publicação ${ }^{9}$, Amaral (1998) apresenta análises de uma pesquisa ${ }^{10}$ nacional realizada pela Associação Nacional dos Dirigentes das Instituições Federais de Ensino Superior (Andifes) em final de 1997. O autor expõe que o problema do financiamento deve ser analisado pelo ângulo das limitações orçamentárias, das instituições, e financeira, dos estudantes e da população brasileira, e apresenta argumentos utilizados em defesa da gratuidade do ensino superior e em favor de uma maior participação do estudante nos custos de seus estudos. Conclui em favor da gratuidade do ensino nas instituições públicas.

Sobre a evolução do custo do aluno nas IFES brasileiras, Amaral (2004) publica artigo no qual utiliza a modelagem ${ }^{11}$, proposta por ele em 2002, para análise do período de 1995 a 2001. Conclui que houve uma redução importante no custo do aluno das IFES a partir da redução no volume dos recursos a elas destinados e da expansão no número de alunos. Apresenta questionamentos sobre a qualidade da educação desenvolvida e sobre a relevância das instituições na sociedade. 
Em publicação mais recente, Amaral (2008) apresenta uma discussão sobre o processo de autonomia e financiamento das IFES, com destaque para o período de 1995-2006. O autor analisa as origens do financiamento das IFES e a expansão do ensino superior, tratando dos limites impostos pela desigualdade social à expansão do setor privado. Conclui alertando para os desafios e as ações a serem implementadas nas IFES, considerando as necessidades de desenvolvimento institucional e de autonomia universitária, bem como seu papel institucional na correção das desigualdades regionais brasileiras.

Nessas publicações do periódico Avaliação: Revista da Avaliação da Educação Superior, o tema do financiamento foi considerado em discussões sobre o sistema federal de ensino do Brasil, sobre as instituições públicas federais e sobre perfil sócio-econômico e custo do aluno.

\section{Revista Brasileira de Educação (RBE)}

Ao pesquisar publicações sobre o financiamento da Educação Superior no periódico Revista Brasileira de Educação, observamos que essa temática é considerada de forma secundária, e não central, no desenvolvimento dos trabalhos. A despeito de nosso objetivo de analisar as produções que utilizaram o tema citado com foco principal da pesquisa, decidimos referenciar os escassos artigos dessa revista com o propósito de alertar para a pouca importância dispensada à discussão do financiamento da Educação Superior no Brasil na produção dos pesquisadores da Associação Nacional de Pós-Graduação e Pesquisa em Educação (Anped).

Dois artigos tratam da continuidade da agenda dos organismos internacionais nos governos FHC e Lula. No primeiro, Silva Júnior e Sguissardi (2005) analisam o anteprojeto de lei da reforma universitária e abordam temas sobre a parceria público-privado e financiamento do ensino superior. Sobre os princípios da relação público-privado, argumentam que as políticas para a Educação Superior devam ser políticas públicas de Estado e que as IES privadas sejam somente alternativas quando o Estado não consiga atender sozinho à demanda. A respeito do financiamento da Educação Superior pública, concluem que o mesmo deva ser estatal, em prol do fortalecimento da própria universidade. Para os autores, o exame do anteprojeto mostra, dentre outros aspectos, que uma lei de Educação Superior deve visar a garantia do financiamento público para atender à expansão e à gratuidade da mesma.

O artigo de Goulart e Leher (2008) apresenta considerações sobre o discurso dos organismos internacionais e sua relação com as políticas nacionais. Os autores analisam publicações do Banco Mundial (BM) e abordam a materialidade de um novo imperialismo dos Estados Unidos. Explicitam a 
reconfiguração da Educação Superior do Brasil a partir de marcos normativos e da comodificação da educação. Finalizam, citando a educação a distância, em crescimento exponencial, como mais uma mudança congruente com a agenda do BM; além da descaracterização do conceito de universidade (agora chamada de instituição terciária).

Nas duas publicações do periódico Revista Brasileira de Educação, observamos que o tema do financiamento foi discutido em contextos sobre a ação de organismos internacionais, em análise de anteprojeto da nova lei da reforma universitária brasileira e ao tratar de políticas de expansão.

\section{Revista Brasileira de Estudos Pedagógicos (RBEP)}

A análise das edições da RBEP disponíveis em meio eletrônico, no site do Instituto Nacional de Estudos e Pesquisas Educacionais Anísio Teixeira (INEP), evidenciou que, no período de 1996 a 2009, o tema financiamento da Educação Superior foi abordado de forma ampla, sendo inserido na discussão sobre gastos e custos em educação. Assim, nos artigos que tratam do financiamento, é possível encontrar dados e questões relativas à Educação Superior; esta não se constitui, contudo, em tema exclusivo. Especificamente sobre o financiamento da Educação Superior, não encontramos artigos que tratem desse assunto como foco central de análise, sendo ele abordado de forma secundária em nove textos que tratam sobre política de financiamento da educação em geral. O financiamento é relacionado às seguintes temáticas: fundos públicos; fiscalização dos recursos e papel dos Tribunais de Contas dos estados; gastos públicos com educação e vinculação constitucional.

Dois artigos abordam a discussão sobre fundos públicos de financiamento para a educação. No artigo de Teixeira (1999) ${ }^{12}$ é apresentado o cenário brasileiro do início da década de 1950, do século XX. O objetivo do artigo é propor alternativas para o financiamento da educação pública no Brasil. As principais estratégias defendidas são os fundos de educação ou fundos escolares. O autor argumenta que, a despeito dos dispositivos constitucionais destinarem recursos à educação, esses ainda são insuficientes, pois não criam meios de estender a educação a todos os brasileiros. Assim, o autor propõe a urgência de se transformarem os recursos federais, estaduais e municipais em fundos de educação, com administração especial e autônoma. O que se destaca na ideia de fundos escolares é a autonomia de cada ente da federação para gerir as verbas destinadas à educação.

O estudo feito por Parente (2006) objetiva descrever o formato da Assistência Financeira do Fundo Nacional de Desenvolvimento da Educação (FNDE) no recorte espaço-temporal de 1997 a 1999. Utilizando como fontes 
da pesquisa os documentos do FNDE e entrevistas com técnicos e gestores dessa autarquia, busca descrever o formato da Assistência Financeira do FNDE a programas e projetos educacionais, via Plano de Trabalho Anual (PTA). Destaca que a principal fonte de receita, mas não a exclusiva, do FNDE é o Salário-Educação. A autora conclui que a Assistência Financeira do FNDE possui limitações quanto à aplicação dos recursos da quota federal do salárioeducação, principalmente devido ao seu formato, desvelando que o modelo apresenta tanto problemas técnicos quanto problemas de credibilidade política, em virtude das "transferências negociadas", ou seja, da utilização do poder político-partidário para a obtenção do recurso ou para a aceleração de seu recebimento.

Davies $(1999,2007)$ publica dois artigos em que trata da questão relativa à fiscalização dos recursos da educação em geral, com destaque para a atuação dos Tribunais de Contas. No texto de 1999, o autor se detém na análise da atuação do Tribunal de Contas do Estado do Rio de Janeiro (TCERJ) no período de agosto de 1985 a dezembro de 1996. No artigo, publicado em 2007, analisa a atuação do Tribunal de Contas de Mato Grosso (TCE-MT), examinando os procedimentos desse tribunal para a contabilização da receita e despesa vinculada à Manutenção e Desenvolvimento do Ensino (MDE) no período de 1996 a 2001. O objetivo dos dois artigos é mostrar a pouca confiabilidade dos órgãos estatais no que se refere à aplicação (Secretarias de Educação) e fiscalização (Tribunais de Contas) dos recursos vinculados à educação. Na análise da atuação dos dois tribunais, o autor demonstrou a existência de falhas técnicas nos pareceres e desvelou a existência de equívocos e oscilação nas interpretações desses órgãos de fiscalização. Após exaustiva análise, o autor conclui questionando a eficácia desses Tribunais uma vez que, além dos equívocos de interpretação, eles não aplicam nenhuma punição aos estados pelas práticas de irregularidades e denuncia que os problemas técnicos evidenciados no estudo ligam-se a questões de ordem político-partidária e as reforçam.

Dois artigos analisam os gastos públicos com a educação brasileira. No primeiro, Almeida (2001) tem por objetivo mostrar as principais mudanças no financiamento ocorridas no Brasil no período de 1994 a 1999, o que permite, por um lado, discutir o padrão de gasto realizado pelo governo brasileiro no sistema educacional público e, por outro, realizar comparações entre as regiões brasileiras, os países da América do Sul e os países-membros da Organização para Cooperação e Desenvolvimento Econômico (OCDE). O artigo pretende mostrar um caminho possível para o tratamento de informações relativas a financiamento e gasto público com educação, utilizando-se dos balanços gerais de estados e municípios e do Sistema Integrado de Ad- 
ministração Financeira (Siafi) do governo federal. Destaca que, na Educação Superior o gasto por aluno é determinado por uma combinação de três fatores essenciais: tipo de instituição, pesquisa e esfera de governo.

O artigo de Pinto (2001) apresenta resultados de estudo feito por um grupo de trabalho criado para analisar o financiamento da educação brasileira. No texto, são analisados os gastos do Brasil com a educação, considerando o poder público e as famílias. Também é feita uma discussão sobre os recursos necessários para um ensino de qualidade, considerando a necessidade de cumprimento das metas do PNE e o impacto da criação do Fundo Nacional de Financiamento da Educação Básica (Fundeb) para as finanças dos três níveis de governo. São apresentados dados estatísticos sobre: gastos públicos com a educação em todos os níveis e esferas governamentais, percentuais do PIB, gasto por aluno por nível de escolarização, gastos das famílias com educação e, ainda, salários dos professores, comparados como os de outros profissionais do serviço público. A principal conclusão do relatório é que, para atingir os novos patamares de atendimento em qualidade e quantidade definidos pelo PNE, o Brasil deveria sair do atual patamar de gastos públicos em educação, da ordem de $4,3 \%$ do PIB, para atingir, em dez anos, o montante de $8 \%$ do PIB.

Dois artigos abordam a discussão sobre vinculação constitucional de recursos. Sena (2002) analisa historicamente a vinculação dos impostos na manutenção e desenvolvimento do ensino. Identifica a pressão do Poder Executivo, em todos os níveis federativos, pela desvinculação de recursos - o que já ocorre na esfera da União, com a decorrente redução da base de cálculo e, portanto, dos recursos da educação. Já Jesus (2007) tem por objetivo compreender o processo de efetivação das propostas relacionadas ao financiamento e à instituição da vinculação de verbas para a educação, originada na Constituição de 1934. Trata-se de um texto de caráter histórico, com ênfase nos aspectos formais e jurídicos, cujas fontes de pesquisa foram os Anais e Diários da Assembléia Nacional Constituinte de 1933-1934 e os Decretos editados pelo Governo Provisório de Vargas (1931-1934).

O objetivo do artigo de Gouveia (2009) é defender a pertinência de caracterizar as disputas no campo da política educacional brasileira a partir do binômio direita e esquerda. A autora argumenta que esse binômio pode sintetizar propostas antagônicas de educação que disputam a direção das políticas governamentais em curso, com repercussões na forma de utilização dos recursos para a educação. Apresenta uma revisão da bibliografia sobre os partidos políticos no Brasil e uma revisão acerca das análises de propostas de política educacional pós-ditadura militar. A partir dessa revisão, construiu uma matriz que pretende sintetizar as disputas educacionais nos âmbitos das políticas de acesso, gestão e financiamento da educação. 
De um modo geral, os textos publicados na RBEP apresentam resultados de estudos e pesquisas de fundamental importância para a compreensão do financiamento da educação, mesmo que com enfoques diferenciados e em períodos históricos distintos. Apesar de não terem como eixo central a questão do financiamento da Educação Superior, pode-se afirmar que as reflexões feitas contribuem de forma significativa para a análise da política de financiamento adotada no país e apresentam propostas interessantes sobre a aplicação e a fiscalização dos recursos da educação, bem como sobre a necessidade de ampliar de forma significativa os recursos para a educação no país.

\section{CONSIDERAÇÕES FINAIS}

Os textos produzidos no período de 1996 a 2009 sobre financiamento da Educação Superior publicados nos periódicos nacionais aqui destacados refletem as questões emergentes referentes a essa temática nesse período histórico, expressando importantes elementos da conjuntura política e econômica vivenciada no país e seus reflexos na definição dos recursos aplicados na educação brasileira. De modo geral, os artigos denunciam as estratégias que os sucessivos governos vêm adotando na política de financiamento, as quais têm contribuído para a manutenção da crise da educação de modo geral e, em especial, da Educação Superior, que permanece excluindo a maioria da população da possibilidade de ter acesso a esse nível de ensino.

O balanço da produção escrita sobre o financiamento da Educação Superior no período destacado indica a necessidade de se ampliarem e se aprofundarem os estudos acerca dessa temática, em especial em dois dos periódicos aqui analisados - Revista Brasileira de Educação e Revista Brasileira de Estudos Pedagógicos, onde identificamos a não existência de artigos que abordam a temática como eixo central.

BRAZILIAN HIGHER EDUCATION FUNDING POLICIES: A CRITICAL ASSESSMENT OF SCIENTIFIC PRODUCTION IN THE 1996-2009 PERIOD

AвSTRACT: this article presents results of the first phase of the ongoing research entitled 'Funding policies for Higher Education expansion in post-LDB Brazil', and presents a critical assessment of the scientific production on the theme of higher education funding policies, in the 1996-2009 period. Articles published in five national journals were selected for the research. The results indicate that there is a scarcity of research on the theme and point to the need for further studies on higher education funding because of its relevance for the understanding of educational policies.

KEYWORDs: Funding policies. Public resources. Public funds. Related funds. 


\section{NOTAS}

1. Qualis Periódicos, Ano-Base 2008, disponível em: http://qualis.capes.gov.br/webqualis/ConsultaPeriodicos.faces

2. Periódico publicado pela Anped, disponível em: http://www.anped.org.br/rbe/ rbe/rbe.htm

3. Periódico publicado pelo Centro de Estudos Educação \& Sociedade - Unicamp, disponível em http://www.cedes.unicamp.br/rev_apresentacao.htm

4. Periódico publicado pela Universidade de Sorocaba - Uniso, disponível em http:// www.scielo.br/scielo.php?script=sci_issues\&pid=1414-4077\&lng=pt\&nrm=iso

5. Periódico publicado pelo Instituto Nacional de Estudos e Pesquisas Educacionais Anísio Teixeira - Inep, disponível em http://rbep.inep.gov.br/index.php/RBEP

6. Periódico publicado pela Associação Nacional dos Docentes do Ensino Superior Andes, disponível em http://www.andes.org.br/universidadeesociedade.htm

7. De 1997 a 2004, exceto o ano 2000, a periodicidade da revista foi quadrimestral.

8. Desde 1995 é publicado, anualmente, um número especial da revista, tornado-a um periódico trimestral.

9. Publicação a partir do Centro Interdisciplinar de Pesquisa para o esenvolvimento da Educação Superior (Cipedes), adicionada ao periódico Avaliação sob a forma de separata.

10. A pesquisa citada objetivou traçar o perfil sócio-econômico e cultural dos estudantes de graduação das instituições de federais de ensino superior (IFES).

11. Metodologia que considera as atividades de ensino, pesquisa e extensão,para o cálculo do custo do aluno para as IFES, ao mesmo tempo que não considera o pagamento de inativos, pensionistas e precatórios como gastos relacionados ao custo do aluno.

12. O artigo foi originalmente publicado na Revista Brasileira de Estudos Pedagógicos de 1953 e reeditado em 1999.

\section{REFERÊNCIAS}

ALMEIDA, I. C. Gastos com educação no período de 1994 a 1999. R. Bras. Est. Pedag., Brasília, v. 82, n. 200/201/202, p. 137-198, jan./dez, 2001.

AMARAL, N. C. Autonomia e financiamento das IFES: desafios e ações. Avaliação, Campinas; Sorocaba, SP, v. 13, n. 3, p. 647-680, nov., 2008.

Evolução do custo do aluno das IFES: eficiência? Avaliação, Campinas, v. 9, n. 2, p. 115-124, 2004.

. O Financiamento do Ensino Superior Público no Brasil: dos jesuítas a FHC. Universidade e Sociedade. Brasília, Ano XIII, n. 30, p. 55-63, jun., 2003.

. O perfil sócio-econômico dos alunos de graduação e o financiamento das IFES: dez argumentos a favor da gratuidade. Avaliação, Campinas; Sorocaba, SP, v. 3, n. 3(9), p. 15-24, set., 1998. 
. O sistema federal de ensino superior brasileiro: organização e financiamento. Avaliação, Campinas; Sorocaba, SP, v. 2, n. 13, p. 25-40, mar., 1997.

BOSI, A. P.; REIS, L. F. Autonomia universitária, luta docente e a questão dos repasses mínimos para as universidades. Universidade e Sociedade. Brasília, Ano XIII, n. 30, p. 82-91, jun., 2003.

CARNEIRO, M. L. F. Dívida pública: o centro dos problemas nacionais. Universidade e Sociedade. Brasília, Ano XVIII, n. 42, p. 25-35, jun., 2008.

CARVALHO, C. H. A. O PROUNI no governo Lula e o jogo político em torno do acesso ao ensino superior. Educ. Soc., Campinas, v. 27, n. 96 (especial), p. 979-1000, out., 2006.

CHAVES, V. L. J. Política de Ciência e Tecnologia e o Financiamento da pesquisa no Brasil. Universidade e Sociedade. Brasília, Ano XVIII, n. 42, p. 77-87, jun., 2008.

; VASCONCELOS, H. C. A Temática - política de financiamento da educação - na revista Universidade e Sociedade. Universidade e Sociedade. Brasília, Ano XIII, n. 30, p. 55-63, jun., 2003.

CORBUCCI, Paulo Roberto. Financiamento e democratização do acesso à Educação Superior no Brasil: da deserção do Estado ao projeto de reforma. Educ. Soc., Campinas, vol.25, n. 88, p. 677-701, out., 2004.

DAVIES, N. Aplicação dos recursos vinculados à educação: as verificações do Tribunal de Contas de Mato Grosso. R. Bras. Est. Pedag., Brasília, v. 88, n. 219, p. 345-362, maio-ago., 2007.

. O Financiamento da educação Superior no Governo Lula: uma loteria? Universidade e Sociedade. Brasília, Ano XV, n. 35, p. 83-95, fev., 2005.

. O governo Lula e a educação: a deserção do Estado continua? Educ. Soc., Campinas, v. 25, n. 86, p. 245-252, abr., 2004.

O Financiamento público às escolas privadas. Universidade e Sociedade. Brasília, Ano XVI, n. 27, p.74-91, jun., 2002.

Plano Nacional de Educação: muito discurso, nenhum recurso. Universidade e Sociedade. Brasília, Ano XI, n. 25, p. 29-39, dez., 2001.

Tribunal de Contas: faz as contas ou faz-de-conta na avaliação dos gastos governamentais com educação. R. Bras. Est. Pedag., Brasília, v. 80, n. 194, p. 19-27, jan./ abr., 1999.

. Os Recursos Financeiros na LDB. Universidade e Sociedade. Brasília, Ano VII, n. 14, p. 19-27, jun., 1997.

GOULART, R.; LEHER, R. Do discurso e das condicionalidades do Banco Mundial, a Educação Superior "emerge" terciária. Rev. Bras. Educ., Rio de Janeiro, RJ, v. 13, n. 39, p. 423-436, set./dez., 2008. 
GOUVEIA, A. B. Direita e esquerda na política educacional: Democracia, partidos e disputas entre projetos de administração pública municipal no Brasil. R. Bras. Est. Pedag., Brasília, v. 90, n. 224, p. 32-58, jan./abr., 2009.

HELENE, O. Comentários Sobre o Financiamento do Ensino Superior. Universidade e Sociedade. Brasília, Ano XIV, n. 33, p. 64-67, jun., 2004.

JESUS, W. F. O "problema nacional": a história de uma emenda que transformou o financiamento da educação no Brasil. R. Bras. Est. Pedag., Brasília, v. 88, n. 220, p. 477495, set./dez., 2007.

LIMA, K. REUNI e Banco de Professor Equivalente: novas ofensivas da contra-reforma da Educação Superior brasileira no Governo Lula da Silva. Universidade e Sociedade. Brasília, Ano XIX, n. 41, p. 69-77, jan., 2008.

; LIMA, S. L. R. Dívida pública e Educação Superior. Universidade e Sociedade. Brasília, Ano XV, n. 37, p. 59-71, mar., 2006.

MIRAGLIA, F.; SMAILI, S. O Financiamento Público para a Universidade Pública é Necessário. Universidade e Sociedade. Brasília, Ano XIV, n² 26, p. 32-36, fev., 2002.

OLIVEIRA, R. P. A transformação da educação em mercadoria no Brasil. Educ. Soc., Campinas, v. 30, n. 108, p. 739-760, out., 2009.

PARENTE, C. M. D. Assistência financeira do FNDE/MEC a programas e projetos educacionais: formato e implicações. R. Bras. Est. Pedag., Brasília, v. 87, n. 215, p. 19-28, jan./abr., 2006.

PINTO, J. M. R. O acesso à Educação Superior no Brasil. Educ. Soc., Campinas, v. 25, n. 88, p. 727-756, out., 2004.

. Relatório do Grupo de Trabalho sobre Financiamento da Educação. R. Bras. Est. Pedag., Brasília, v. 82, n. 200/201/202, p. 117-136, jan./dez., 2001.

PINTO, M. B.; LIMA, S. L. R.; CISLAGUI, J. F. Universidade pública e crise atual. Universidade e Sociedade. Brasília, Ano XIX, n. 44, p. 75-81, jun., 2009.

SENA, P. A União e a aplicação dos recursos vinculados à manutenção e ao desenvolvimento do ensino. R. Bras. Est. Pedag., Brasília, v. 83, n. 203/204/205, p. 7-22, jan./ dez., 2002.

SEVILHA, Valdemar. A Herança Orçamentária do que já veio e do que está por vir. Universidade e Sociedade. Brasília, Ano VIII, n. 17, p. 34-35, nov., 1998.

SGUISSARDI, V. Universidade pública estatal: entre o público e o privado-mercantil. Educ. Soc., Campinas, vol. 26, n. 90, p. 191-222, jan., 2005.

SILVA JÚNIOR, J. R.; SGUISSARDI, V. A nova lei de Educação Superior: fortalecimento do setor público e regulação do privado/mercantil ou continuidade da privatização e mercantilização do público? Rev. Bras. Educ., Rio de Janeiro, RJ, n. 29, p. 5-23, mai./ jun./jul./ago., 2005. 
SIQUEIRA, A. C. Educação Superior em Disputa: expansão excludente versus democratização da universidade critica. Universidade e Sociedade. Brasília, Ano XVIII, n. 43, p. 155-167, jun. 2009.

TEIXEIRA, A. Sobre o problema de como financiar a educação do povo brasileiro: bases para a discussão do financiamento dos sistemas públicos de educação. R. Bras. Est. Pedag., Brasília, v. 80, n. 194, p. 102-113, jan./abr., 1999.

TONEGUTTI, C. A. Financiamento da Educação Pública: elementos para reflexão. Universidade e Sociedade. Brasília, Ano XVI, n. 39, p. 29-35, fev., 2007.

; MARTINEZ, M. O REUNI e a precarização nas IFES. Universidade e Sociedade. Brasília, Ano XVII, n. 41, p. 51-67, jan., 2008.

VELLOSO, J.; MARQUES, P. M. F. Recursos próprios da UNB, o financiamento das IFES e a reforma da Educação Superior. Educ. Soc., Campinas, v. 26, n.91, p. 655-680, maio, 2005.

VERA LÚCIA JACOB CHAVES é doutora em Educação pela UFMG,
professora associada I do Instituto de Ciências da Educação da Universi-
dade Federal do Pará e coordenadora do Grupo de Estudos e Pesquisas
sobre Educação Superior (GEPES) da UFPA.
E-mail: vjacob@uol.com.br

André Rodrigues GuImARÃes é doutorando em Educação na UFPA, professor Assistente I do Curso de Pedagogia da Universidade Federal do Amapá e membro do Grupo de Estudos e Pesquisas sobre Educação Superior (GEPES) da UFPA.

E-mail:andre@unifap.br

Nabiha Haddad SimÕes Machado Mestre e Doutoranda em Educação pela UnB. Professora das Faculdades Integradas da União Educacional do Planalto Central.

E-mail:nabiha@unb.br. 